\title{
Effects of COVID-19 on in-hospital cardiac arrest: incidence, causes, and outcome - a retrospective cohort study
}

Kevin Roedl ${ }^{1 *}$ (D, Gerold Söffker ${ }^{1}$, Dominik Fischer ${ }^{2}$, Jakob Müller ${ }^{1,3}$, Dirk Westermann ${ }^{4}$, Malte Issleib², Stefan Kluge ${ }^{1}$ and Dominik Jarczak

\begin{abstract}
Background: Severe acute respiratory syndrome coronavirus-2 (SARS-CoV-2), an emerging virus, has caused a global pandemic. Coronavirus disease 2019 (COVID-19), caused by SARS-CoV-2, has led to high hospitalization rates worldwide. Little is known about the occurrence of in-hospital cardiac arrest (IHCA) and high mortality rates have been proposed. The aim of this study was to investigate the incidence, characteristics and outcome of IHCA during the pandemic in comparison to an earlier period.
\end{abstract}

Methods: This was a retrospective analysis of data prospectively recorded during 3-month-periods 2019 and 2020 at the University Medical Centre Hamburg-Eppendorf (Germany). All consecutive adult patients with IHCA were included. Clinical parameters, neurological outcomes and organ failure/support were assessed.

Results: During the study period hospital admissions declined from 18,262 (2019) to 13,994 (2020) (-23\%). The IHCA incidence increased from 4.6 (2019: 84 IHCA cases) to 6.6 (2020: 93 IHCA cases)/1000 hospital admissions. Median stay before IHCA was 4 (1-9) days. Demographic characteristics were comparable in both periods. IHCA location shifted towards the ICU (56\% vs 37\%, $p<0.01$ ); shockable rhythm (VTNF) (18\% vs 29\%, $p=0.05$ ) and defibrillation were more frequent in the pandemic period ( $20 \%$ vs $35 \%, p<0.05)$. Resuscitation times, rates of ROSC and post-CA characteristics were comparable in both periods. The severity of illness (SAPS II/SOFA), frequency of mechanical ventilation and frequency of vasopressor therapy after IHCA were higher during the 2020 period. Overall, 43 patients (12 with \& 31 without COVID-19), presented with respiratory failure at the time of IHCA. The Horowitz index and resuscitation time were significantly lower in patients with COVID-19 (each $p<0.01$ ). Favourable outcomes were observed in 42 and 10\% of patients with and without COVID-19-related respiratory failure, respectively.

Conclusion: Hospital admissions declined during the pandemic, but a higher incidence of IHCA was observed. IHCA in patients with COVID-19 was a common finding. Compared to patients with non-COVID-19-related respiratory failure, the outcome was improved.

Keywords: COVID-19, Corona virus disease, Multiple organ failure, Intensive care unit, SARS-COV-2, Cardiac arrest, Cardiopulmonary resuscitation, In-hospital cardiac arrest

\footnotetext{
* Correspondence: k.roedl@uke.de

1 Department of Intensive Care Medicine, University Medical Centre Hamburg-Eppendorf, Martinistraße 52, 20246 Hamburg, Germany Full list of author information is available at the end of the article
}

(C) The Author(s). 2021 Open Access This article is licensed under a Creative Commons Attribution 4.0 International License, which permits use, sharing, adaptation, distribution and reproduction in any medium or format, as long as you give appropriate credit to the original author(s) and the source, provide a link to the Creative Commons licence, and indicate if changes were made. The images or other third party material in this article are included in the article's Creative Commons licence, unless indicated otherwise in a credit line to the material. If material is not included in the article's Creative Commons licence and your intended use is not permitted by statutory regulation or exceeds the permitted use, you will need to obtain permission directly from the copyright holder. To view a copy of this licence, visit http://creativecommons.org/licenses/by/4.0/ The Creative Commons Public Domain Dedication waiver (http://creativecommons.org/publicdomain/zero/1.0/) applies to the data made available in this article, unless otherwise stated in a credit line to the data. 


\section{Background}

Originating from Wuhan, China, a series of pneumonias of initially unknown cause emerged in December 2019 $[1,2]$. A novel coronavirus (severe acute respiratory syndrome coronavirus 2 (SARS-CoV-2)) spread and caused a pandemic $[3,4]$. Although many patients have a mild course of disease, a considerable number of patients suffer from severe illness with rapid progression to acute respiratory distress syndrome (ARDS) or/and end-organ failure [1-3].

COVID-19 has resulted in high rates of hospitalization and a high number of patients requiring intensive care unit (ICU) treatment $[5,6]$. The course of disease can be complicated, and can potentially lead to cardiac arrest (CA) for several reasons, as shown by various studies [7-10]. An increase in out-of-hospital cardiac arrest (OHCA) cases was observed during the COVID-19 pandemic $[11,12]$. However, little is known about the CA risk in hospitalized patients with COVID-19 [10, 13-15]. Poor in-hospital survival following in-hospital cardiac arrest (IHCA) in patients with COVID-19 has been described, and mortality ranged from 88 to $100 \%[9,10$, 13, 15]. However, data on in-hospital cardiac arrest (IHCA) in patients with respiratory failure with and without COVID-19 are scarce.

In general, an estimated 290,000 adults suffer from IHCA in the United States annually [16, 17]. IHCA is often unexpected and presents as an acute event; every hospitalized patient can potentially be affected. Different studies have shown abnormal vital signs as predictors of IHCA $[18,19]$. Therefore, rapid response teams and the use of warning scores have been established [20]. Although most IHCAs occur in general wards [21, 22], a considerable number of IHCAs occur in the ICU [23]. The incidence of IHCA varies greatly in the literature (1-5/1000 hospital admissions) [16, 17]. Rates of survival to hospital discharge range from 13 to $22 \%$ [24].

However, data on IHCA during the COVID-19 pandemic are very limited. In the present study we aimed to investigate the occurrence, determinants, outcome and post-CA course of patients suffering from IHCA during the COVID-19 pandemic and before.

\section{Methods}

\section{Study population, design and ethics}

This was a retrospective analysis of data prospectively recorded at the University Medical Centre HamburgEppendorf (Germany). All consecutive adult patients suffering an IHCA during a 3-month period in 2019 and 2020 were included. The following time periods were compared: 2019 (February 27-May 28) and 2020 (February 27-May 27). For post-CA care all patients were treated at the Department of Intensive Care Medicine, which cares for all critically ill adult patients of the hospital and includes 12 ICUs (total capacity: 142 ICU beds). The study complied with the Declaration of Helsinki. The Ethics Committee of the Hamburg Chamber of Physicians was informed about the study (No.: WF-152/20). The requirement for informed patient consent was waived due to the use of only anonymized data collected during routine clinical care. The last day of follow-up was September 30, 2020.

\section{Inclusion and exclusion criteria}

We included all consecutive adult patients ( $\geq 18$ years) with an IHCA event. Patients $<18$ years of age and patients or with a prior OHCA event and/or re-arrest after hospital admission were not considered as an incident IHCA and were therefore excluded.

\section{Study definitions and patient management}

IHCA was defined as cessation of circulation, and therefore, an indication for chest compression and/or cardiac defibrillation in patients who had a pulse and circulation at the time of hospital admission. Sustained return of spontaneous circulation (ROSC) was defined as stable circulation for at least $20 \mathrm{~min}$. Assessment of neurological outcome was performed within routine clinical practice using cerebral performance categories (CPCs) after the IHCA and during follow-up. A CPC score of 1-2 was defined as a favourable neurological outcome, and a score of 3-5 was defined as an unfavourable neurological outcome. Survival was assessed through the end of the ICU stay. Cardiopulmonary resuscitation and post-CA care were performed in accordance with the European Resuscitation Council guidelines [25]. Data were collected according to Utstein-style guidelines [26]. Cardiac failure was defined as the need for inotrope/vasopressors (dobutamine, epi-/norepinephrine) during the first $72 \mathrm{~h}$ after CA [27]. Hypoxic liver injury (HLI) was diagnosed according to established criteria [28]. COVID-19 was defined as a positive result on a reverse transcriptase-polymerase chain reaction, and only laboratory-confirmed cases were counted as COVID-19. ARDS was defined using the $\mathrm{PaO}_{2} / \mathrm{FiO}_{2}$ ratio (Horowitz index) according to the Berlin definition [29-31]. The severity of illness was evaluated by the sequential organ failure assessment (SOFA) score [32] and simplified acute physiology (SAPS II) [33] score. The Charlson comorbidity index (CCI) [34] was calculated in all patients.

\section{Data collection}

Data were collected through electronic patient data management systems (PDMS, Integrated Care Manager ${ }^{\circ}$ (ICM), Version 9.1 - Draeger Medical, Luebeck, Germany; Soarian Clinicals, Version 4.3.200 - Cerner Health Service, Inc.) and consisted of age, sex, comorbidities, admission diagnosis, length of ICU-stay, 
treatment modalities, organ support (mechanical ventilation, vasopressor, renal replacement therapy (RRT), blood transfusions, antibiotics, antivirals, etc.), laboratory parameters and further clinical parameters of interest through the end of ICU-stay. Pre-existing medication was recorded based on known regular medications and medication on admission. Laboratory assessment was performed daily as part of the clinical routine.

\section{Statistical analysis}

The results are presented as counts and relative frequencies or medians and $25-75 \%$ interquartile ranges (IQRs). Binary variables were compared via chi-square analysis/ Fisher's exact test, as appropriate. Metric variables were compared via the Mann-Whitney U test. We used multivariable Cox regression to investigate factors associated with mortality and unfavourable outcomes. Factors of clinical relevance were selected and included. A $p$-value $<0.05$ was considered statistically significant. Statistical analysis was conducted using IBM SPSS Statistics Version 24.0 (IBM Corp., Armonk, NY). The study was prepared in accordance with the STROBE (STrengthening the Reporting of OBservational studies in Epidemiology) recommendations.

\section{Results}

\section{Study population}

During the two study time periods, namely 2019-nonCOVID-19 (February 27-May 28) and 2020-COVID-19 (February 27-May 27), a total of 18,262 and 13,994 inpatients were treated at the University Medical Centre Hamburg-Eppendorf, respectively. We identified 84
(2019-non-COVID-19 period) and 93 (2020-COVID-19 period) patients suffering from IHCA during the two study periods; these patients were included in the present study (see Study Flow-Chart Fig. 1).

\section{Baseline and cardiac arrest characteristics of the study population}

Detailed baseline and IHCA characteristics are shown in Tables 1 and 2. Patients were predominantly male (68\%, $n=120)$; the median age was $70(57-78)$ years. In this study, comorbidities were frequent, and a median CCI of $3(2-5)$ was observed. Arterial hypertension $(67 \%, n=$ 118) was the leading comorbidity. Furthermore, common comorbidities were history of malignant condition (tumour, haematologic malignancy) $(33 \%, n=58)$, coronary heart disease (35\%, $n=62)$, diabetes mellitus type II $(21 \%, n=38)$, chronic respiratory disease $(20 \%, n=36)$ and chronic kidney disease $(18 \%, n=32)$. The reasons for hospital admission were medical in $74 \%(n=131)$ of the patients, unplanned surgery in $14 \%(n=24)$ and planned surgical in $13 \%(n=22)$. The median duration from hospital admission to IHCA was 4 (1-9) days. The IHCA location was non-ICU in $53 \%(n=94)$. The initial cardiac rhythm was shockable (VT/VF) in $24 \%(n=42)$; defibrillation during CPR was performed in $28 \%(n=50)$. The median total resuscitation time was $5(2-17) \mathrm{mi}-$ nutes. Sustained ROSC was observed in $80 \%(n=142)$, and cardiac re-arrest was observed in $30 \%(n=53)$. A mechanical chest compression system was used in $11 \%$ $(n=19)$. Aetiology of the IHCA was presumed cardiac in $37 \%(n=66)$. Due to refractory IHCA 5\% $(n=9)$ received extracorporeal-CPR (E-CPR).

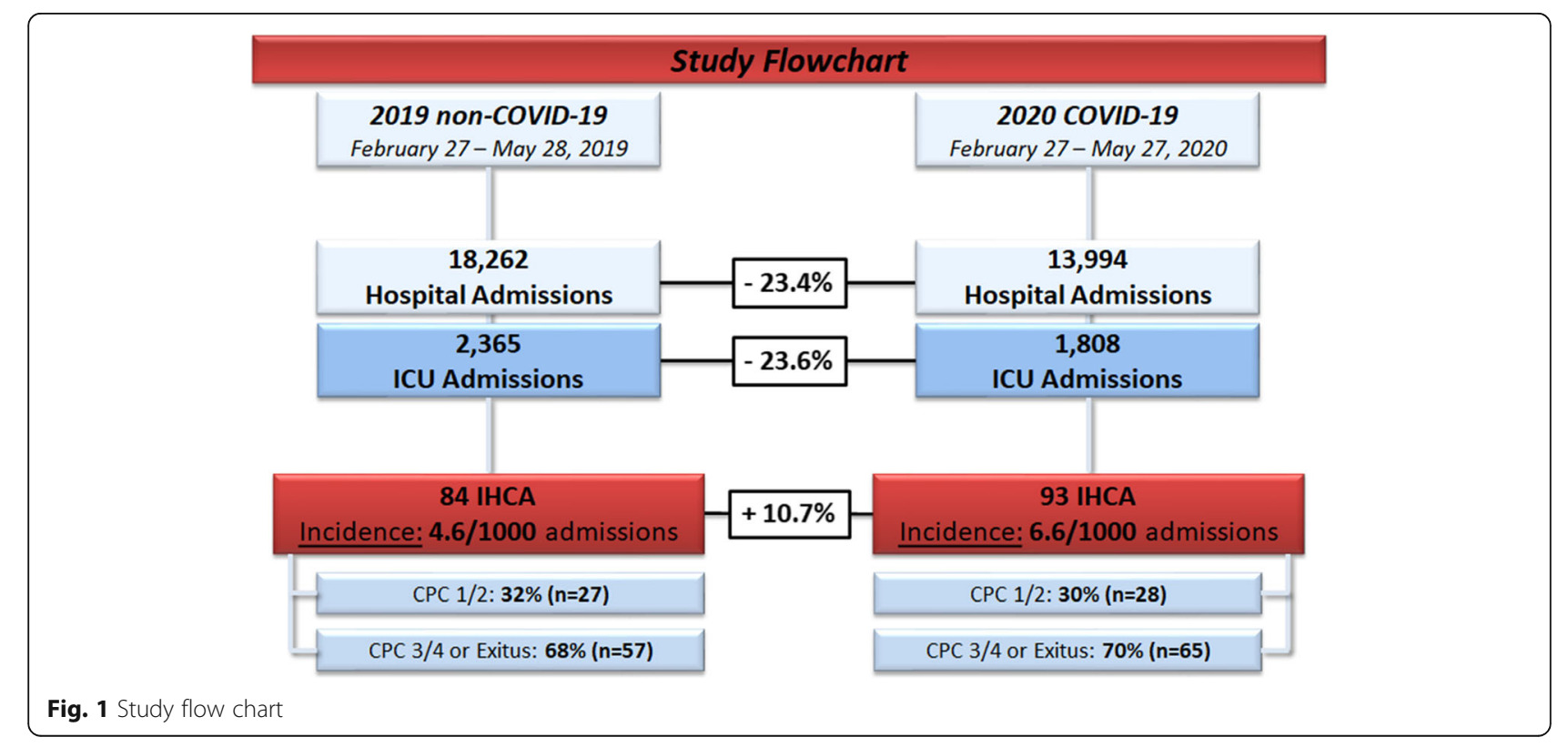


Table 1 Baseline characteristics of patients with in-hospital cardiac arrest stratified according the 2019 (Non-COVID-19) and 2020 (COVID-19) period

\begin{tabular}{|c|c|c|c|c|}
\hline Parameters & $\begin{array}{l}\text { All patients } \\
(n=177)\end{array}$ & $\begin{array}{l}2019-\text { Non-COVID-19 Period } \\
(n=84)\end{array}$ & $\begin{array}{l}2020-\text { COVID-19 Period } \\
(n=93)\end{array}$ & $p$-value \\
\hline \multicolumn{5}{|l|}{ Demographics } \\
\hline Age, years median (IQR) & $70(57-78)$ & $72(57-78)$ & $68(57-78)$ & 0.721 \\
\hline Sex, male $n(\%)$ & $120(68)$ & $60(71)$ & $60(65)$ & 0.206 \\
\hline Height, cm median (IQR) & $172(165-180)$ & $175(168-180)$ & $170(165-179)$ & 0.109 \\
\hline Weight, kg median (IQR) & $76(65-85)$ & $73(65-84)$ & $78(67-86)$ & 0.207 \\
\hline $\mathrm{BMI}, \mathrm{kg} / \mathrm{m}^{2}$ median (IQR) & $25(23-29)$ & $25(23-27)$ & $26(24-29)$ & 0.077 \\
\hline \multicolumn{5}{|l|}{ Comorbidities } \\
\hline Charlson comorbidity index, pts.; median (IQR) & $3(2-5)$ & $3(2-5)$ & $3(2-5)$ & 0.802 \\
\hline Arterial hypertension, $n$ (\%) & $118(67)$ & $49(58)$ & $69(74)$ & 0.019 \\
\hline Coronary heart disease, $n$ (\%) & $66(37)$ & $29(35)$ & $33(35)$ & 0.510 \\
\hline Chronic kidney disease, $n$ (\%) & $32(18)$ & $13(15)$ & $19(20)$ & 0.255 \\
\hline Chronic respiratory disease, $n$ (\%) & $36(20)$ & $20(24)$ & $16(17)$ & 0.183 \\
\hline Diabetes, $n(\%)$ & $38(21)$ & $20(24)$ & $18(19)$ & 0.312 \\
\hline Malignant condition, $n$ (\%) & $58(33)$ & $23(27)$ & $35(38)$ & 0.098 \\
\hline \multicolumn{5}{|l|}{ COVID-19 } \\
\hline Confirmed COVID-19, n (\%) & $12(7)$ & - & $12(13)$ & \\
\hline Positive test to ICU, days median (IQR) & $10(3-17)$ & - & $10(3-17)$ & \\
\hline Positive test to IHCA, days median (IQR) & $17(14-28)$ & - & $17(14-28)$ & \\
\hline Cough, $n(\%)$ & - & - & $7(58)^{a}$ & \\
\hline Shortness of breath, $n$ (\%) & - & - & $3(25)^{a}$ & \\
\hline Fever, $n(\%)$ & - & - & $6(50)^{a}$ & \\
\hline Fatigue, $n$ (\%) & - & - & $3(25)^{\mathrm{a}}$ & \\
\hline Myalgia, $n(\%)$ & - & - & $1(8)^{a}$ & \\
\hline \multicolumn{5}{|l|}{ Reason of hospital admission } \\
\hline \multicolumn{5}{|l|}{ Surgical } \\
\hline planned, $n$ (\%) & $22(13)$ & $7(8)$ & $15(16)$ & 0.089 \\
\hline unplanned, $n$ (\%) & $24(14)$ & $14(17)$ & $10(11)$ & 0.177 \\
\hline Medical, $n(\%)$ & $131(74)$ & $63(75)$ & $68(73)$ & 0.455 \\
\hline \multicolumn{5}{|l|}{ Characteristics - before CA } \\
\hline Heart rate /min; median (IQR) & $91(77-111)$ & $91(80-108)$ & $91(75-111)$ & 0.922 \\
\hline MAP mmHg; median (IQR) & $70(62-82)$ & $72(66-82)$ & $70(60-82)$ & 0.549 \\
\hline \multicolumn{5}{|l|}{ Outcome } \\
\hline Overall mortality, $n$ (\%) & $95(54)$ & $41(49)$ & $54(58)$ & 0.140 \\
\hline Discharged from ICU alive, $n$ (\%) & $82(46)$ & $43(51)$ & $39(42)$ & 0.140 \\
\hline Length of stay - ICU, days median (IQR) & $5(2-17)$ & $6(2-17)$ & $5(2-16)$ & 0.592 \\
\hline
\end{tabular}

Abbreviations: $\mathrm{cm}$ Centimeter; BMI Body mass index; $\mathrm{kg}$ Kilogram; ICU Intensive care unit; IQR Interquartile range; $n$ Number; $p t s$. Points; min Minute; MAP Mean arterial pressure; COVID-19 Coronavirus disease 2019; IHCA In-hospital cardiac arrest; ${ }^{\text {a }}$ in relation to positive tested patients $(n=12)$

\section{Differences during the pandemic period and before}

Tables 1 and 2 show a comparison of the detailed baseline and IHCA characteristics comparing between the study periods. During the 2020-COVID-19 period hospital admissions and ICU admissions declined from 18, 262 to $13,994(-23 \%)$ and from 2365 to $1808(-24 \%)$, respectively. The incidence of IHCA increased from 4.6 to $6.6 / 1000$ hospital admissions. Demographic characteristics (age, sex and BMI) and comorbidities (as measured by $\mathrm{CCI}$ ) were comparable between the groups. Arterial hypertension was significantly more common in patients during the COVID-19 period (2019 Non-COVID-19 period: $58 \%$ vs 2020 COVID-19 period: $74 \%$ ). The most common reason for hospital admission was medical care, 
Table 2 Cardiac arrest and ICU-characteristics of the study cohort stratified in the 2019 (No-COVID-19) and 2020 (COVID-19) period

\begin{tabular}{|c|c|c|c|c|}
\hline Parameters & $\begin{array}{l}\text { All patients } \\
(n=177)\end{array}$ & $\begin{array}{l}2019-\text { No-COVID-19 } \\
(n=84)\end{array}$ & $\begin{array}{l}2020-\text { COVID }-19 \\
(n=93)\end{array}$ & $p$-value \\
\hline \multicolumn{5}{|l|}{ Cardiac arrest Characteristics } \\
\hline Location of IHCA & & & & 0.009 \\
\hline$I C U, n(\%)$ & $83(47)$ & $31(37)$ & $52(56)$ & \\
\hline Non-ICU, n (\%) & $94(53)$ & $53(63)$ & $41(44)$ & \\
\hline Initial rhythm - shockable (VTNF), n (\%) & $42(24)$ & $15(18)$ & $27(29)$ & 0.058 \\
\hline Defibrillation, $n(\%)$ & $50(28)$ & $17(20)$ & $33(35)$ & 0.018 \\
\hline Sustained ROSC, $n$ (\%) & $142(80)$ & $65(77)$ & $77(83)$ & 0.237 \\
\hline Cardiac re-arrest, $n(\%)$ & $53(30)$ & $27(32)$ & $26(30)$ & 0.329 \\
\hline Presumed cardiac cause, $n(\%)$ & $66(37)$ & $35(42)$ & $31(33)$ & 0.161 \\
\hline Epinephrine - total dose, mg, median (IQR) & $2(1-4)$ & $2(1-4)$ & $2(1-4)$ & 0.978 \\
\hline \multicolumn{5}{|l|}{ Resuscitation time, min; median (IQR) } \\
\hline No-flow & $0(0-0)$ & $0(0-0)$ & $0(0-0)$ & 0.300 \\
\hline Total resuscitation time & $5(2-17)$ & $4(1.5-14)$ & $5(2-20)$ & 0.204 \\
\hline Targeted temperature management, $n(\%)$ & $56(32)$ & $27(32)$ & $29(31)$ & 0.509 \\
\hline Use of mechanical compression system, $n(\%)$ & $19(11)$ & $12(14)$ & $7(8)$ & 0.114 \\
\hline $\mathrm{E}-\mathrm{CPR}, n(\%)$ & $9(5)$ & $5(6)$ & $4(4)$ & 0.436 \\
\hline \multicolumn{5}{|l|}{ ICU - Characteristics } \\
\hline \multicolumn{5}{|l|}{ Severity of illness } \\
\hline SAPS II (pts.) median (IQR) & $45(35-55)$ & $44(35-56)$ & $47(35-54)$ & 0.837 \\
\hline SOFA - after CA (pts.) median (IQR) & $12(9-14)$ & $11(8-13)$ & $12(10-14)$ & 0.060 \\
\hline SOFA - $24 \mathrm{~h}$ after CA (pts.) median (IQR) & $11(7-14)$ & $11(7-14)$ & $11(8-14)$ & 0.923 \\
\hline \multicolumn{5}{|l|}{ Physiological parameters - post CA } \\
\hline Heart rate - after CA median (IQR) & $96(77-115)$ & $94(77-110)$ & $96(77-125)$ & 0.232 \\
\hline MAP - after CA median (IQR) & $73(63-88)$ & $76(62-92)$ & $72(63-82)$ & 0.324 \\
\hline \multicolumn{5}{|l|}{ Lab values - post CA median (IQR) } \\
\hline Lactate - highest after CA, mmol/l & $4.5(1.9-9.1)$ & $4.8(2-9.1)$ & $4.4(1.9-8.2)$ & 0.965 \\
\hline pH - lowest after CA & $7.26(7.07-7.36)$ & $7.26(7.07-7.34)$ & $7.26(7.10-7.36)$ & 0.755 \\
\hline \multicolumn{5}{|l|}{ Procedures/Complications - post CA } \\
\hline Mechanical ventilation, $n(\%)$ & $124(70)$ & $55(65)$ & $69(74)$ & 0.031 \\
\hline Vasopressor therapy, $n$ (\%) & $120(68)$ & $49(58)$ & $71(76)$ & 0.025 \\
\hline Renal replacement therapy, $n$ (\%) & $26(15)$ & $11(13)$ & $15(16)$ & 0.243 \\
\hline Coronary angiography, $n$ (\%) & $21(12)$ & $14(17)$ & $7(8)$ & 0.050 \\
\hline Hypoxic liver injury, $n$ (\%) & $35(20)$ & $16(19)$ & $19(20)$ & 0.484 \\
\hline Cholestasis - bilirubin > 2 mg/dl, $n$ (\%) & $45(25)$ & $22(26)$ & $23(25)$ & 0.480 \\
\hline
\end{tabular}

Abbreviations: CA Cardiac arrest; $E$-CPR Extracorporeal cardiopulmonary resuscitation; ICU Intensive care unit; IQR Inter quartile range; $n$ Number; min Minute; $m g$ Milligram; mmol/I Millimole per liter; pts. Points; ROSC Return of spontaneous circulation; SAPS Simplified Acute Physiology Score; SOFA Sequential Organ Failure Assessment; VF Ventricular Fibrillation; VT Ventricular Tachycardia; MAP Mean arterial pressure; COVID-19 Coronavirus disease 2019; IHCA In-hospital cardiac arrest

which did not differ between the time periods. The IHCA location was primarily non-ICU during 2019-nonCOVID-19 period and primarily in the ICU during the 2020-COVID-19 period $(p<0.01)$. A shockable rhythm (18\% vs $29 \%$ ) was more frequently observed during the COVID-19 period, and the use of defibrillation $(20 \%$ vs $35 \%)$ was significantly higher. The rates of sustained ROSC (77\% vs $83 \%)$, cardiac re-arrest (32\% vs $30 \%)$ and total epinephrine use ( $2 \mathrm{mg}$ vs $2 \mathrm{mg}$ ) were comparable in both study periods. The median resuscitation time was $4 \mathrm{~min}$ vs. $5 \mathrm{~min}$ and did not differ significantly between the groups. Mechanical compression systems were used more frequently during the 2019 period (14\% vs 8\%). Targeted temperature management post-CA was used in $32 \%$ of patients in the whole cohort, and the frequency was similar in both study periods. The SAPS II and 
SOFA score post-CA were higher during the 2020COVID-19 period. During the ICU stay mechanical ventilation was performed more frequently during the 2020 -COVID-19 period (65\% vs $74 \%, p<0.05$ ). Vasopressor therapy was more commonly used during the 2020-COVID-19 period (58\% vs 76\%). Liver dysfunction was frequent during both study periods; $20 \%$ suffered from hypoxic liver injury and $25 \%$ suffered from cholestasis.

\section{IHCA and COVID-19}

During the aforementioned 2020 time period, 144 patients with COVID-19 were treated as inpatients at our centre. Of these, 75 patients were treated in the normal ward, and 69 patients were critically ill and therefore treated in the ICU. Twelve patients (10\%) with COVID19 treated at our hospital suffered from IHCA. All patients had severe respiratory failure either due to pneumonia or due to the development of ARDS. The median times from the first positive SARS-CoV-2 test to the ICU and to IHCA were 10 (3-17) days and 17 (1428) days, respectively. The most common symptoms of COVID-19 were cough $(n=7 ; 58 \%)$, fever $(n=6 ; 50 \%)$, shortness of breath and fatigue ( $n=3$ for each, $25 \%)$. None of the IHCAs occurred outside the ICU. All patients had a primary non-shockable rhythm (PEA/Asystole) and ROSC. The median resuscitation time was1.5 (0.5-3.5) minutes. For detailed characteristics of patients with COVID-19, see Tables 1, 2, 3 and Supplementary Tables 1 and 2.

\section{Characteristics of IHCA in patients with or without COVID- 19 related severe respiratory failure}

Detailed characteristics are shown in Table 3 and Supplementary Table 1 and 2. Overall, $25 \%(n=43)$ of patients had severe respiratory failure at the time of IHCA and were selected. Of those $28 \%(n=12)$ suffered from COVID-19 pneumonia. Demographic characteristics (age, sex, BMI) were comparable between patients with severe respiratory failure who did not have COVID-19. Comorbidities, represented by the CCI were significantly lower (4 vs 2 points; $p<0.01$ ) in patients with nonCOVID-19 related severe respiratory failure. In total, $68 \%$ received non-invasive or invasive mechanical ventilation prior to IHCA. Overall, $56 \%(n=24)$ of patients suffered from ARDS at the time of IHCA and ARDS was more frequently observed in patients with COVID-19. In addition, the Horowitz index after IHCA was significantly lower in patients with COVID-19. ARDS management, including prone positioning, neuromuscular blockage, corticosteroids and inhaled vasodilatory treatment, was comparable in both groups. IHCA within the ICU was significantly more frequent in patients with COVID-19 than in those without COVID-19-related severe respiratory failure. The most common initial rhythm was non-shockable in both groups. The use of epinephrine was comparable in both groups. The total resuscitation time was longer in patients with nonCOVID-19 related severe respiratory failure (median 5 vs $1.5 \mathrm{~min} ; p<0.01$ ). The severity of illness at ICU admission and after IHCA was comparable between the groups. During the ICU stay, RRT was more frequent $(p<0.01)$ in patients with COVID-19. Laboratory values before and after IHCA were comparable between the groups. Furthermore, physiological parameters before and after IHCA did not differ significantly.

\section{Survival and functional outcome}

Of the 177 included patients who had an IHCA event, 99 (54\%) did not survive the ICU-stay. Fifty-six patients (32\%) died within $24 \mathrm{~h}$ after the IHCA. At ICU discharge $31 \%(n=55)$ had favourable neurological outcomes (CPC I/II). Rates did not differ significantly between the two study periods (2019: 32\% - 2020: 30\%). In patients with COVID-19, the rates of favourable neurological outcomes (CPC I/II) were higher than those in patients with nonCOVID-19-related severe respiratory failure (42\% vs $10 \%)$. Cox regression analysis revealed that the SOFA-score after IHCA [HR 1.17, 95\% CI (1.00-1.36); $p<0.05]$, CCI [HR $1.13,95 \% \mathrm{CI}(1.01-1.26) ; p<0.05]$ and low-flow time [HR $1.07,95 \%$ CI $(1.01-1.12) ; p<0.05]$ were significantly associated with unfavourable neurological outcome or ICUmortality within patients with severe respiratory failure (see Supplementary Table 3).

\section{Discussion}

In this study investigating the effects of the COVID-19 pandemic on IHCA, we found that the incidence of IHCA was increased, the location of IHCA shifted towards the ICU and CA-characteristics were changed. To our knowledge, this is the first study evaluating the effect of the COVID-19 pandemic on IHCA. Furthermore, this is the first study comparing the IHCA characteristics of patients suffering from severe respiratory failure that was and was not related to COVID-19 at time the of IHCA.

The COVID-19 pandemic led to a higher incidence of OHCA and worse short-term outcomes [11, 12]. Different mechanisms suggesting direct effects of COVID-19 and effects from lockdown were proposed [35]. However, to date, no data on how the pandemic has affected IHCA exist. Due to the rapid spread and surge of patients with COVID-19, elective admissions to hospitals were cancelled to create more capacity for patients suffering from COVID-19. This was impressively demonstrated by a $23 \%$ decrease in hospital admissions during the COVID-19 period. Although hospital admissions decreased substantially, an $11 \%$ increased incidence of IHCA was observed. The reported incidence of IHCA in 
Table 3 Cardiac arrest characteristics of patients with severe respiratory failure with and without COVID-19

\begin{tabular}{|c|c|c|c|c|}
\hline Parameters & $\begin{array}{l}\text { All patients } \\
(n=43)\end{array}$ & $\begin{array}{l}\text { Severe respiratory } \\
\text { failure no-COVID-19 } \\
(n=31)\end{array}$ & $\begin{array}{l}\text { Severe respiratory } \\
\text { failure - COVID-19 } \\
(n=12)\end{array}$ & $p$-value \\
\hline \multicolumn{5}{|l|}{ Demographics } \\
\hline Age, years median (IQR) & $65(50-75)$ & $65(50-77)$ & $65(56-74)$ & 0.565 \\
\hline Sex, male, $n$ (\%) & $34(79)$ & $25(81)$ & $9(75)$ & 0.471 \\
\hline $\mathrm{BMI}, \mathrm{kg} / \mathrm{m}^{2}$ median (IQR) & $27(24-31)$ & $26(24-30)$ & $28(26-33)$ & 0.314 \\
\hline Charlson comorbidity index, pts. median (IQR) & $3(1.5-6)$ & $4(2.5-6)$ & $2(1-2)$ & 0.003 \\
\hline \multicolumn{5}{|l|}{ Characteristics of respiratory failure } \\
\hline \multicolumn{5}{|l|}{ Respiratory support (before CA) } \\
\hline Non-invasive ventilation $n$ (\%) & $7(16)$ & $3(10)$ & $4(33)$ & 0.125 \\
\hline Mechanical ventilation $n$ (\%) & $22(51)$ & $17(55)$ & $5(42)$ & 0.148 \\
\hline \multicolumn{5}{|l|}{ Cause of respiratory failure (at CA) } \\
\hline Pneumonia $n(\%)$ & $37(86)$ & $25(81)$ & $12(100)$ & 0.001 \\
\hline ARDS $n(\%)$ & $24(56)$ & $12(39)$ & $10(83)$ & 0.000 \\
\hline \multicolumn{5}{|l|}{ Horowitz index $\left(\mathrm{PaO}_{2} / \mathrm{FiO}_{2}\right.$-ratio $)$} \\
\hline Worst Horowitz index, mmHg, median (IQR) & $84(57-148)$ & $90(57-149)$ & $82(59-107)$ & 0.503 \\
\hline Horowitz index after $\mathrm{CA}, \mathrm{mmHg}$, median (IQR) & $97(76-145)$ & $101(78-152)$ & $89(69-19)$ & 0.007 \\
\hline \multicolumn{5}{|l|}{ ARDS Management } \\
\hline Prone Positioning $n$ (\%) & $8(19)$ & $2(6)$ & $6(50)$ & 0.437 \\
\hline Neuromuscular Blockage $n$ (\%) & $6(14)$ & $1(3)$ & $5(42)$ & 0.306 \\
\hline Corticosteroids $n$ (\%) & $11(26)$ & $4(13)$ & $7(58)$ & 0.563 \\
\hline Inhaled Vasodilators $n$ (\%) & $9(21)$ & $3(10)$ & $6(50)$ & 0.437 \\
\hline \multicolumn{5}{|l|}{ Cardiac arrest Characteristics } \\
\hline Location & & & & 0.009 \\
\hline ICU, n (\%) & $37(86)$ & $25(81)$ & $12(100)$ & \\
\hline Non-ICU, n (\%) & $6(14)$ & $6(19)$ & $0(0)$ & \\
\hline Initial Rhythm - Shockable (VTNF), n (\%) & $6(14)$ & $6(19)$ & $0(0)$ & 0.255 \\
\hline Sustained ROSC, $n(\%)$ & $40(93)$ & $28(90)$ & $12(100)$ & 0.364 \\
\hline Epinephrine - total dose, mg, median (IQR) & $1(1-2)$ & $2(1-2.5)$ & $1(1-1.3)$ & 0.310 \\
\hline \multicolumn{5}{|l|}{ Resuscitation time, min; median (IQR) } \\
\hline No-Flow & $0(0-0)$ & $0(0-0)$ & $0(0-0)$ & 1 \\
\hline Total resuscitation time & $4(1.8-8.5)$ & $5(2-10)$ & $1.5(0.5-3.5)$ & 0.008 \\
\hline Targeted temperature management, $n$ (\%) & $10(23)$ & $8(26)$ & $2(17)$ & 0.339 \\
\hline $\mathrm{E}-\mathrm{CPR}, n(\%)$ & $0(0)$ & $0(0)$ & $0(0)$ & 1 \\
\hline \multicolumn{5}{|l|}{ ICU - Characteristics } \\
\hline \multicolumn{5}{|l|}{ Severity of illness } \\
\hline SAPS II (pts.) median (IQR) & $44(36-52)$ & $42(35-49)$ & $50(40-56)$ & 0.485 \\
\hline SOFA - after CA (pts.) median (IQR) & $14(12-16)$ & $14(12-17)$ & $15(13-16)$ & 0.202 \\
\hline SOFA - $24 \mathrm{~h}$ after CA (pts.) median (IQR) & $13(11-16)$ & $13(11-15)$ & $14(10-16)$ & 0.145 \\
\hline \multicolumn{5}{|l|}{ Lab values - post CA median (IQR) } \\
\hline Lactate - highest after CA, mmol/l & $4.6(1.6-8.5)$ & $4.8(1.5-10)$ & $4.2(3.1-4.8)$ & 0.765 \\
\hline $\mathrm{pH}$ - lowest after CA & $7.21(7.15-7.32)$ & $7.22(7.06-7.32)$ & 7.2 (7.19-7.3) & 0.889 \\
\hline
\end{tabular}


Table 3 Cardiac arrest characteristics of patients with severe respiratory failure with and without COVID-19 (Continued)

\begin{tabular}{|c|c|c|c|c|}
\hline Parameters & $\begin{array}{l}\text { All patients } \\
(n=43)\end{array}$ & $\begin{array}{l}\text { Severe respiratory } \\
\text { failure no-COVID-19 } \\
(n=31)\end{array}$ & $\begin{array}{l}\text { Severe respiratory } \\
\text { failure - COVID-19 } \\
(n=12)\end{array}$ & $p$-value \\
\hline \multicolumn{5}{|l|}{ Procedures/Complications - post CA } \\
\hline Vasopressor therapy, $n(\%)$ & $40(93)$ & $29(94)$ & $11(92)$ & 0.505 \\
\hline Renal replacement therapy, $n$ (\%) & $22(51)$ & $12(39)$ & $10(83)$ & 0.009 \\
\hline Coronary angiography, $n$ (\%) & $0(0)$ & $0(0)$ & $0(0)$ & 1 \\
\hline Hypoxic liver injury, $n$ (\%) & $11(26)$ & $7(23)$ & $4(33)$ & 0.201 \\
\hline Cholestasis - bilirubin $>2$ mg/dl, $n(\%)$ & $15(58)$ & $10(32)$ & $5(42)$ & 0.190 \\
\hline
\end{tabular}

Abbreviations: CA Cardiac arrest; $\mathrm{Cm}$ Centimeter; $E$-CPR Extracorporeal cardiopulmonary resuscitation; ICU Intensive care unit; IQR Inter quartile range; $k g$ Kilogram; $n$ Number; min Minute; mg Milligram; mmol/l Millimole per liter; pts. Points; ROSC Return of spontaneous circulation; SAPS Simplified Acute Physiology Score; SOFA Sequential Organ Failure Assessment; VF Ventricular Fibrillation; VT Ventricular Tachycardia; MAP Mean arterial pressure; COVID-19 Coronavirus disease 2019; IHCA In-hospital cardiac arrest; BMI Body mass index

the literature is $1-5 / 1000$ hospital admissions; during the pandemic period, the incidence of 6.6/1000 hospital admissions exceeded reported rates [16, 17]. Different factors could explain this finding. First, patients with COVID-19 are at high risk of IHCA due to rapidly worsening respiratory failure eventually leading to IHCA if not promptly treated. Of interest, explainable deterioration of $\mathrm{SpO}_{2}$ and high $\mathrm{FiO}_{2}$, but only minor abnormalities in other vital signs, as well as higher early warning scores, have recently been described as predictors for outcome $[36,37]$. Second, the severity of illness at ICU admission was substantially higher than that in the non-COVID-19 period. Although an early ICU admission strategy was followed, this may be explained by delayed or disrupted contact with the healthcare system due to lockdown measures, leading to delayed hospital admission in general.

Furthermore, we observed substantial differences according to IHCA characteristics during the study periods. During the pandemic period, the IHCA location shifted more towards the ICU, which may be explained by earlier ICU admission of deteriorating patients. Moreover, the rate of shockable rhythm and defibrillation increased and we observed high rates of ROSC. These observed differences are potentially explained by higher rates of IHCA occurring in the ICU and a faster response to deterioration due to higher nurse/doctor staffing. Interestingly, the duration of resuscitation was slightly longer during the pandemic period. CPR, an aerosol-generating procedure, exposes healthcare workers to a risk of viral transmission. Therefore, the use of personal-protective equipment is of central importance but could have contributed to the delayed initiation of CPR. Furthermore, the lower rate of presumed cardiac aetiology is important. However, resuscitation times were shorter than those in previous studies [23].

Overall, one quarter of patients presented with an initial shockable rhythm, which is in line with previous studies and can be explained by the low rate of cardiac aetiology of the IHCA. However, half of the patients were in the ICU before IHCA and suffered from high severity of illness, and the rate of $\mathrm{MV}$ and vasopressor support was associated with a nonshockable rhythm [38, 39].

The occurrence of IHCA among hospitalized patients with COVID-19 commonly ranges from 6 to 14\% [9, $10]$. We confirmed these results and found an incidence of $8 \%$. The outcome after IHCA in patients with COVID-19 is worse, and high mortality rates, ranging from 88 to $100 \%$, have been reported $[9,10,13,15,40]$. These reports led to a controversial discussion about futility and appropriateness of care in patients suffering from COVID-19. However, in our small cohort, we observed a distinctly lower mortality than previously reported, although we observed comparable IHCA characteristics, including similar rates of non-shockable initial rhythm, resuscitation time and occurrence of IHCA in the ICU. The lower mortality in our cohort can be a consequence of several reasons. First, a considerably lower number of patients were on MV or RRT before $\mathrm{CA}$, demonstrating a lower severity of illness. Moreover, we followed a strategy of early admission to the ICU in patients with COVID-19 for closer monitoring and early initiation of supportive care. This could also correspond to the high rate of ROSC observed in our cohort and is probably related to continuous monitoring and higher nurse/doctor staffing. Second, earlier reports originated from regions with an excessive case load which potentially led to overwhelmed healthcare systems playing an important role in appropriate patient care [13, 15]. However, decisions on futility and withholding CPR are difficult and must be based on a multifactorial approach that takes the severity of illness, current organ support and the patient's directive into account.

SARS-CoV-2 primarily affects the respiratory system which can lead to rapid deterioration and severe respiratory failure. Recent clinical studies reported high 


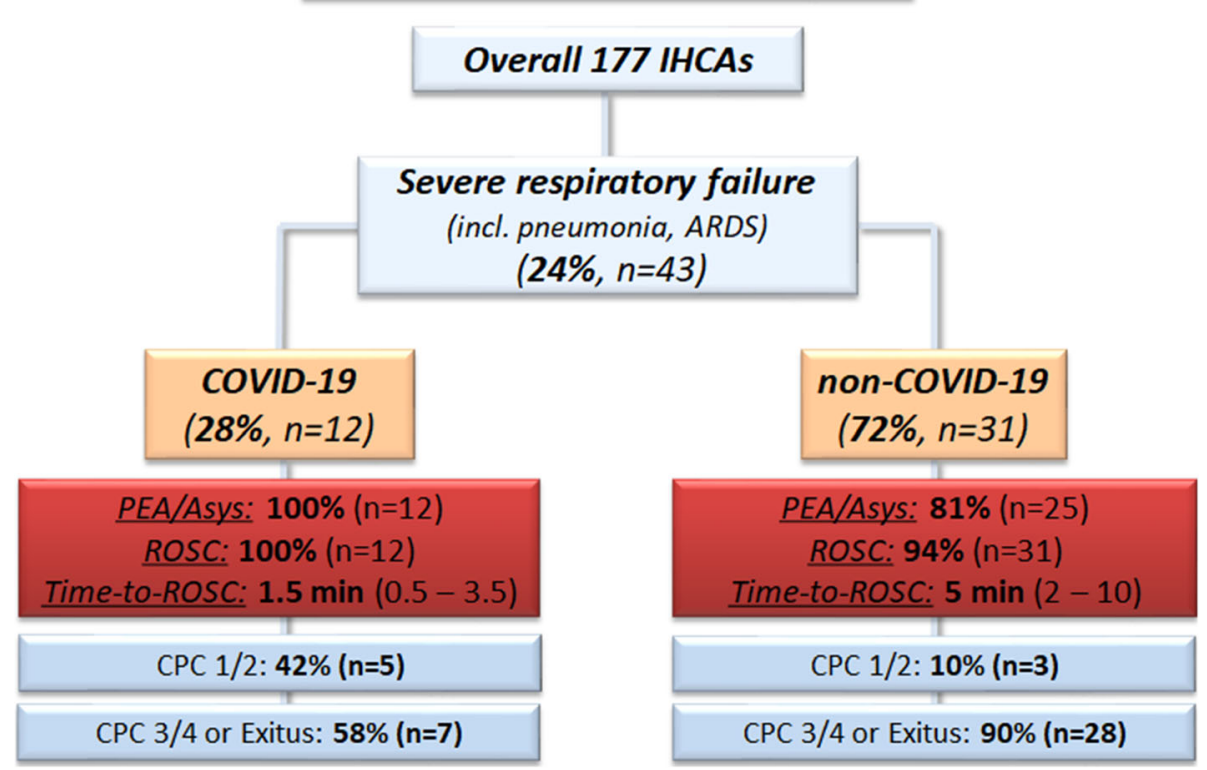

Fig. 2 Outcome of patients with severe respiratory failure - stratified to COIVD-19 and non-COVID-19

mortality following IHCA events in patients with COVID-19 [9, 10, 13]. As patients with COVID-19 primarily suffer from respiratory failure, comparing the characteristics and outcomes of IHCA to patients suffering from respiratory failure related and not related to COVID-19 seems reasonable. However, this is the first study comparing patients with severe respiratory failure not related to COVID-19 at the time of IHCA with patients suffering from COVID-19. We observed that patients with COVID-19 had a lower comorbidity rate and substantially lower Horowitz index before and after IHCA. In patients suffering from ARDS, we observed comparable therapeutic approaches. Furthermore, a high rate of IHCA occurring in the ICU was observed, and correspondingly, a substantially lower resuscitation time was observed. In our cohort, we observed that IHCA often occurred during tracheal intubation. This may be a consequence of delayed decisions for tracheal intubation. However, this should lead to higher awareness of the timing of intubation in patients with progredient respiratory failure. A higher number of patients with COVID19 required RRT and had liver injury (HLI/cholestasis) contributing to the higher severity of illness after IHCA. However, direct viral effects cannot be entirely excluded. Moreover, CCI, SOFA scores and resuscitation time were identified as mortality predictors in these patients. Of interest, a substantially higher number of patients with COVID-19 had a favourable outcome compared to other patients with severe respiratory failure (Fig. 2).
Larger future studies must confirm these results and their implications on outcome.

This study has several limitations. First, our study included a small number of patients. Larger cohorts are needed to confirm our findings. Second, the data were derived from a single centre and were collected retrospectively. However, the data were documented prospectively in the PDMS by trained ICU staff. Third, we show the results of an experienced high-volume CA centre. Thus, the results might not generally be transferable to other, less experienced, settings. Fourth, the study was conducted early during the pandemic. Changes in clinical practice, due to more experience with COVID-19, could have changed affecting the incidence and outcome of IHCA especially in critically ill patients.

\section{Conclusions}

In conclusion, this is the first study evaluating IHCA occurrence and outcomes during the COVID-19 pandemic in comparison to recent years. Hospital admissions declined during the pandemic, but a higher incidence of IHCA was observed, which could be attributed to multifactorial influences and must be further evaluated. Approximately $10 \%$ of hospitalized patients with COVID19 suffered from IHCA, and outcomes were improved compared with those previously reported and comparable to those of patients with other aetiologies of respiratory failure not related to COVID-19. 


\section{Supplementary Information}

The online version contains supplementary material available at https://doi. org/10.1186/s13049-021-00846-w.

Additional file 1: Supplementary Table 1. Pre-existing comorbidities of patients with severe respiratory failure at time of cardiac arrest stratified according patients with and without COVID-19. Supplementary Table 2. Characteristics of patients with severe respiratory failure before and after cardiac arrest stratified according with and without COVID-19. Supplementary Table 3. Cox regression model for factors associated with ICU-mortality and unfavorable neurological outcome (CPC III/IV) of patients with IHCA and severe respiratory failure.

\section{Abbreviations}

ARDS: Acute respiratory distress syndrome; Asys: Asystole; BMI: Body mass index; CA: Cardiac arrest; CCl: Charlson comorbidity index; COVID-

19: Coronavirus disease 2019; CPC: Cerebral performance categories; ECPR: Extracorporeal cardiopulmonary resuscitation; HLI: Hypoxic liver injury; ICU: Intensive care unit; IHCA: In-hospital cardiac arrest; IQR: Interquartile range; MV: Mechanical ventilation; OHCA: Out-of-hospital cardiac arrest; PEA: Pulseless electrical activity; ROSC: Return of spontaneous circulation; RRT: Renal replacement therapy; SAPS: Simplified acute physiology score; SARS-CoV-2: Severe acute respiratory syndrome coronavirus 2; SOFA: Sequential organ failure assessment score; VT: Ventricular tachycardia; VF: Ventricular fibrillation

\section{Acknowledgements}

None.

\section{Authors' contributions}

$K R, G S, D J$ and SK participated in study conception and design. KR, GS, JM, $D F, D W, M I$ were involved in acquisition of data. KR, DJ and SK contributed to analysis and interpretation of data. KR drafted the manuscript. SK and DJ were involved in critical revision of the manuscript for important intellectual content. SK, GS and DJ participated in supervision. All authors read and approved the final manuscript

\section{Funding}

No financial support has been received conducting this study.

\section{Availability of data and materials}

The datasets supporting the conclusions of this article are included within the article.

\section{Ethics approval and consent to participate}

The Ethics Committee of the Hamburg Chamber of Physicians was informed about the study (No.: WF-152/20). The requirement for informed patient consent was waived due to the use of anonymized data from routine clinical care only. The study was approved by the local clinical institutional review board and complied with the Declaration of Helsinki.

\section{Consent for publication}

Not applicable.

\section{Competing interests}

$\mathrm{KR}, \mathrm{GS}, \mathrm{DF}, \mathrm{JM}, \mathrm{MI}, \mathrm{DW}$ and DJ do not report any conflicts of interest related to this article. SK received research support by Ambu, E.T.View Ltd., Fisher \& Paykel, Pfizer and Xenios, lecture honorarium from ArjoHuntleigh, Astellas, Astra, Basilea, Bard, Baxter, Biotest, CSL Behring, Cytosorbents, Fresenius, Gilead, MSD, Orion, Pfizer, Philips, Sedana, Sorin, Xenios and Zoll, and consultant honorarium from AMOMED, Astellas, Baxter, Bayer, Fresenius, Gilead, MSD, Pfizer and Xenios. No other potential conflict of interest relevant to this article was reported.

\section{Author details}

'Department of Intensive Care Medicine, University Medical Centre Hamburg-Eppendorf, Martinistraße 52, 20246 Hamburg, Germany. ${ }^{2}$ Department of Anaesthesiology, University Medical Centre Hamburg-Eppendorf, Hamburg, Germany. ${ }^{3}$ Department of Anaesthesia,
Tabea Hospital, Hamburg, Germany. ${ }^{4}$ Department of Interventional and General Cardiology, University Heart Centre Hamburg, Hamburg, Germany.

Received: 13 November 2020 Accepted: 1 February 2021

Published online: 08 February 2021

\section{References}

1. Huang C, Wang Y, Li X, Ren L, Zhao J, Hu Y, et al. Clinical features of patients infected with 2019 novel coronavirus in Wuhan, China. Lancet. 2020;395(10223):497-506.

2. Chen N, Zhou M, Dong X, Qu J, Gong F, Han Y, et al. Epidemiological and clinical characteristics of 99 cases of 2019 novel coronavirus pneumonia in Wuhan, China: a descriptive study. Lancet. 2020;395(10223):507-13.

3. Guan WJ, Ni ZY, Hu Y, Liang WH, Ou CQ, He JX, et al. Clinical characteristics of coronavirus disease 2019 in China. N Engl J Med. 2020;382(18):1708-20.

4. WHO. WHO - World Map - COVID-19. 2020 [https://covid19.who.int/ Accessed online: October, 31st 2020] [Available from: https://covid19.who. int/ - Accessed online: October, 19th 2020].

5. Grasselli G, Pesenti A, Cecconi M. Critical care utilization for the COVID-19 outbreak in Lombardy, Italy: early experience and forecast during an emergency response. JAMA. 2020;323(16):1545-6.

6. Richardson S, Hirsch JS, Narasimhan M, Crawford JM, McGinn T, Davidson $\mathrm{KW}$, et al. Presenting characteristics, comorbidities, and outcomes among 5700 patients hospitalized with COVID-19 in the New York City area. JAMA. 2020;323(20):2052-9

7. Ly A, Alessandri C, Skripkina E, Meffert A, Clariot S, de Roux Q, et al. Rescue fibrinolysis in suspected massive pulmonary embolism during SARS-CoV-2 pandemic. Resuscitation. 2020;152:86-8.

8. Creel-Bulos C, Hockstein M, Amin N, Melhem S, Truong A, Sharifpour M. Acute Cor Pulmonale in critically ill patients with Covid-19. N Engl J Med. 2020;382(21):e70.

9. Shah P, Smith H, Olarewaju A, Jani Y, Cobb A, Owens J, et al. Is cardiopulmonary resuscitation futile in coronavirus disease 2019 patients experiencing in-hospital cardiac arrest? Crit Care Med. 2021;49(2):201-8.

10. Hayek SS, Brenner SK, Azam TU, Shadid HR, Anderson E, Berlin H, et al. Inhospital cardiac arrest in critically ill patients with covid-19: multicenter cohort study. BMJ. 2020;371:m3513.

11. Baldi E, Sechi GM, Mare C, Canevari F, Brancaglione A, Primi R, et al. Out-ofhospital cardiac arrest during the Covid-19 outbreak in Italy. N Engl J Med. 2020

12. Marijon E, Karam N, Jost D, Perrot D, Frattini B, Derkenne C, et al. Out-ofhospital cardiac arrest during the COVID-19 pandemic in Paris, France: a population-based, observational study. Lancet Public Health. 2020.

13. Shao F, Xu S, Ma X, Xu Z, Lyu J, Ng M, et al. In-hospital cardiac arrest outcomes among patients with COVID-19 pneumonia in Wuhan, China. Resuscitation. 2020;151:18-23.

14. Sung C-W, Lu T-C, Fang C-C, Huang C-H, Chen W-J, Chen S-C, et al. Impact of COVID-19 pandemic on emergency department services acuity and possible collateral damage. Resuscitation. Resuscitation. 2020;153:185-6.

15. Sheth V, Chishti I, Rothman A, Redlener M, Liang J, Pan D, et al. Outcomes of in-hospital cardiac arrest in patients with COVID-19 in New York City. Resuscitation. 2020;155:3-5.

16. Andersen LW, Holmberg MJ, Berg KM, Donnino MW, Granfeldt A. In-hospital cardiac arrest: a review. Jama. 2019;321(12):1200-10.

17. Benjamin EJ, Muntner P, Alonso A, Bittencourt MS, Callaway CW, Carson AP, et al. Heart disease and stroke Statistics-2019 update: a report from the American Heart Association. Circulation. 2019;139(10):e56-e528.

18. Nurmi J, Harjola VP, Nolan J, Castrén M. Observations and warning signs prior to cardiac arrest. Should a medical emergency team intervene earlier? Acta Anaesthesiol Scand. 2005;49(5):702-6.

19. Andersen LW, Kim WY, Chase M, Berg KM, Mortensen SJ, Moskowitz A, et al. The prevalence and significance of abnormal vital signs prior to in-hospital cardiac arrest. Resuscitation. 2016;98:112-7.

20. Jones DA, DeVita MA, Bellomo R. Rapid-response teams. N Engl J Med. 2011;365(2):139-46.

21. Sandroni C, Nolan J, Cavallaro F, Antonelli M. In-hospital cardiac arrest: incidence, prognosis and possible measures to improve survival. Intensive Care Med. 2007:33(2):237-45.

22. Nolan JP, Soar J, Smith GB, Gwinnutt C, Parrott F, Power S, et al. Incidence and outcome of in-hospital cardiac arrest in the United Kingdom Nationa Cardiac Arrest Audit. Resuscitation. 2014;85(8):987-92. 
23. Efendijev I, Nurmi J, Castrén M, Skrifvars MB. Incidence and outcome from adult cardiac arrest occurring in the intensive care unit: a systematic review of the literature. Resuscitation. 2014;85(4):472-9.

24. Schluep M, Gravesteijn BY, Stolker RJ, Endeman H, Hoeks SE. One-year survival after in-hospital cardiac arrest: a systematic review and metaanalysis. Resuscitation. 2018;132:90-100.

25. Nolan JP, Soar J, Cariou A, Cronberg T, Moulaert VRM, Deakin CD, et al. European resuscitation council and European Society of Intensive Care Medicine Guidelines for post-resuscitation care 2015: section 5 of the European resuscitation council guidelines for resuscitation 2015. Resuscitation. 2015;95:202-22.

26. Nolan JP, Berg RA, Andersen LW, Bhanji F, Chan PS, Donnino MW, et al. Cardiac Arrest and Cardiopulmonary Resuscitation Outcome Reports: Update of the Utstein Resuscitation Registry Template for In-Hospital Cardiac Arrest: A Consensus Report From a Task Force of the International Liaison Committee on Resuscitation (American Heart Association, European Resuscitation Council, Australian and New Zealand Council on Resuscitation, Heart and Stroke Foundation of Canada, InterAmerican Heart Foundation, Resuscitation Council of Southern Africa, Resuscitation Council of Asia). Resuscitation. 2019;144:166-77.

27. Laurent I, Monchi M, Chiche JD, Joly LM, Spaulding C, Bourgeois B, et al. Reversible myocardial dysfunction in survivors of out-of-hospital cardiac arrest. J Am Coll Cardiol. 2002;40(12):2110-6

28. Fuhrmann V, Jäger B, Zubkova A, Drolz A. Hypoxic hepatitis - epidemiology, pathophysiology and clinical management. Wien Klin Wochenschr. 2010; 122(5-6):129-39.

29. Ranieri VM, Rubenfeld GD, Thompson BT, Ferguson ND, Caldwell E, Fan E, et al. Acute respiratory distress syndrome: the Berlin definition. JAMA. 2012; 307(23):2526-33.

30. Alhazzani W, Møller MH, Arabi YM, Loeb M, Gong MN, Fan E, et al. Surviving Sepsis campaign: guidelines on the management of critically ill adults with coronavirus disease 2019 (COVID-19). Intensive Care Med. 2020;46(5):854-87.

31. Kluge $\mathrm{S}$, Janssens $\mathrm{U}$, Welte $\mathrm{T}$, Weber-Carstens $\mathrm{S}$, Marx G, Karagiannidis C. German recommendations for critically ill patients with COVID-19. Medizinische Klinik, Intensivmedizin und Notfallmedizin. 2020:1-4.

32. Vincent JL, Moreno R, Takala J, Willatts S, De Mendonça A, Bruining H, et al. The SOFA (Sepsis-related organ failure assessment) score to describe organ dysfunction/failure. On behalf of the working group on Sepsis-related problems of the European Society of Intensive Care Medicine. Intensive Care Med. 1996;22(7):707-10.

33. Le Gall JR, Lemeshow S, Saulnier F. A new simplified acute physiology score (SAPS II) based on a European/north American multicenter study. JAMA. 1993;270(24):2957-63.

34. Charlson ME, Pompei P, Ales KL, Mackenzie CR. A new method of classifying prognostic comorbidity in longitudinal studies: development and validation. J Chronic Dis. 1987:40(5):373-83.

35. Lim ZJ, Reddy MP, Afroz A, Billah B, Shekar K, Subramaniam A. Incidence and outcome of out-of-hospital cardiac arrests in the COVID-19 era: a systematic review and meta-analysis. Resuscitation. 2020;157:248-58.

36. Pimentel MAF, Redfern OC, Hatch R, Young JD, Tarassenko L, Watkinson PJ. Trajectories of vital signs in patients with COVID-19. Resuscitation. 2020;156: 99-106.

37. Covino M, Sandroni C, Santoro M, Sabia L, Simeoni B, Bocci MG, et al. Predicting intensive care unit admission and death for COVID-19 patients in the emergency department using early warning scores. Resuscitation. 2020; 156:84-91.

38. Roedl K, Jarczak D, Blohm R, Winterland S, Müller J, Fuhrmann V, et al. Epidemiology of intensive care unit cardiac arrest: characteristics, comorbidities, and post-cardiac arrest organ failure - a prospective observational study. Resuscitation. 2020;156:92-8.

39. Leloup M, Briatte I, Langlois A, Cariou A, Lesieur O. Unexpected cardiac arrests occurring inside the ICU: outcomes of a French prospective multicenter study. Intensive Care Med. 2020.

40. Thapa SB, Kakar TS, Mayer C, Khanal D. Clinical outcomes of in-hospital cardiac arrest in COVID-19. JAMA Intern Med. 2021;181(2):279-81.

\section{Publisher's Note}

Springer Nature remains neutral with regard to jurisdictional claims in published maps and institutional affiliations.

Ready to submit your research? Choose BMC and benefit from:

- fast, convenient online submission

- thorough peer review by experienced researchers in your field

- rapid publication on acceptance

- support for research data, including large and complex data types

- gold Open Access which fosters wider collaboration and increased citations

- maximum visibility for your research: over $100 \mathrm{M}$ website views per year

At BMC, research is always in progress.

Learn more biomedcentral.com/submissions 